\title{
Cyclodextrin in starchy foods
}

\author{
É. Fenyvesi* (i) and L. Szente
}

CycloLab Cyclodextrin Research and Development Laboratory Ltd., Illatos str. 7, 1097 Budapest, Hungary

\section{REVIEW PAPER}

Received: March 8, 2021 • Accepted: April 14, 2021

Published online: June 8, 2021

(C) 2021 The Author(s)

\section{ABSTRACT}

Cyclodextrins are widely used in various fields including food industry. In this review, their role in high carbohydrate-containing, starchy foods are reviewed and discussed. Both the effects as functional ingredients affecting the structural properties of starch and as active ingredients slowing down starch digestion and, as a consequence, decreasing the glycaemic index of starchy foods are overviewed without considering the traditional applications as carriers and stabilisers of aroma and flavour, essential oils, polyunsaturated fatty acids, and other bioactive components to enrich foods, even if they are carbohydrate foods. The effect on starch metabolism is explained by the structural transformations caused by cyclodextrins on starch amylose and amylopectin. Several examples are shown how the technological and sensorial properties of bread, rice products, pasta, and other starchy foods are modified by cyclodextrin supplementation, and how the digestibility is changed resulting in reduced glycaemic and insulinaemic effects.

\section{KEYWORDS}

amylose, amylopectin, cyclodextrin, glycaemic index, metabolism, retrogradation

\section{INTRODUCTION}

Starchy foods as a main source of carbohydrates are important part of a healthy, balanced diet. Digestible carbohydrates provide energy for the body, while the non-digestible ones like cellulose - called fibres - help other food and waste products to move through the gut. Wholegrain bread and breakfast cereals, brown rice, and whole-wheat noodle are good examples for natural fibres,

\footnotetext{
*Corresponding author. Tel.: +361 347 7075. E-mail: fenyvesi.e@cyclolab.hu
} 
which not only help to keep the digestion system in good condition but also give a feeling of satisfaction in the stomach, thus reducing meal intake.

Both starch and cellulose are glucose polymers. While the glucose units are coupled with $\alpha-1 \rightarrow 4$ glycosidic bonds in amylose (and also $\alpha-1 \rightarrow 6$ glycosidic bonds in amylopectin), they are connected by $\beta-1 \rightarrow 4$ glycosidic bonds in cellulose. Amylases are able to hydrolyse the $\alpha-1 \rightarrow 4$ glycosidic bonds, but the $\beta-1 \rightarrow 4$ glycosidic bonds are resistant to the amylolytic enzymes. This is the reason why starch is digestible and cellulose is not by humans.

Starch consists of amylose and amylopectin. Both are glucose polymers, but amylose is of linear, helical structure due to the $\alpha-1 \rightarrow 4$ glycosidic bonds, while amylopectin has branched configuration. Cyclodextrins (CDs) are produced from the amylose helices maintaining $\alpha-1 \rightarrow 4$ glycosidic bonds between the glucopyranose units (Szejtli, 1991).

CDs are non-reducing cyclic carbohydrates obtained from starch by cleavage and cyclisation catalyzed by cyclodextrin glucosyl transferase enzyme (CGTase) (Szejtli, 1988; Crini, 2014; Crini et al., 2018). The three native CDs differ in size: $\alpha$-, $\beta$-, and $\gamma$-CD consist of 6,7 , and 8 glucopyranose units (Fig. 1) and have a doughnut shape with a cavity of rather hydrophobic character and of $0.58,0.78$, and $0.95 \mathrm{~nm}$ in diameter, respectively. The outer surface of these molecules is hydrophilic. Owing to this peculiar structure, CDs are able to include other less hydrophilic molecules within their cavities forming inclusion complexes (Szejtli, 2004; Crini et al., 2018) (Fig. 2). The steric fit of at least a part of the guest molecule into the cavity of host

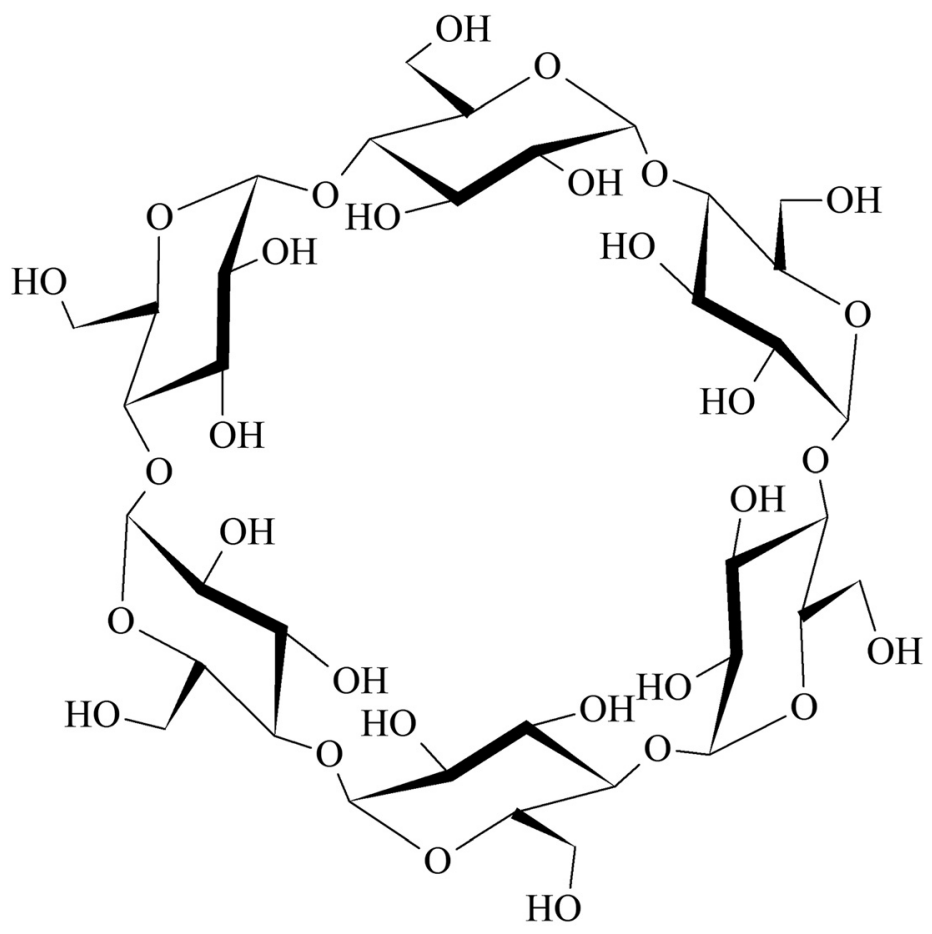

Fig. 1. The structure of $\alpha$-CD 


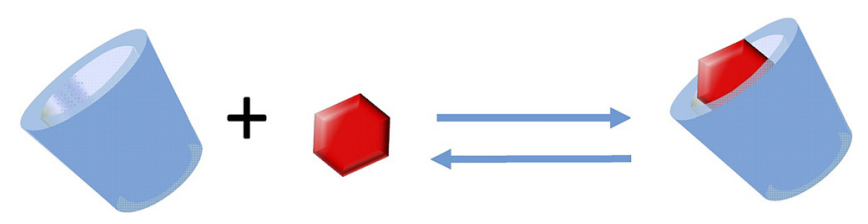

Fig. 2. Scheme of inclusion complex formation via noncovalent interaction between the host $\mathrm{CD}$ and the guest molecule

CDs is one of the most important prerequisite of complex formation. CDs and their complexes have been widely used in various fields including foods.

All three native CDs are on the GRAS (generally accepted as safe) list; $\alpha$ - and $\gamma$-CDs can be consumed without limitation, while for $\beta$-CD a $5 \mathrm{mg} / \mathrm{kg}$ bodyweight/day advisable daily intake (ADI) value was established owing to the potential toxic solvent content (earlier trichloroethylene used to be applied in $\beta$-CD production, although, as far as the authors of this review know, this solvent is not used any more, the ADI limit has not been changed so far (EFSA, 2016)). The regulatory situation of CDs in foods has been recently reviewed by Moreira da Silva (2018).

CDs are used in food industry traditionally as auxiliary agent, a technological aid suitable to improve physico-chemical characteristics of food components, e.g. for stabilising aroma and flavour compounds as well as polyunsaturated fatty acids (PUFAs), solubilising poorly watersoluble vitamins and nutrients, etc, enabling these cyclodextrin-complexed food components to be introduced into industrial scale, automatised food processing technologies. Taste masking, removal of undesired components such as cholesterol from dairy products and eggs, are further examples. These applications have been reviewed by several groups (Szente and Szejtli, 2004; Astray et al., 2009; Martina et al., 2013; Fenyvesi et al., 2016; Astray et al., 2020; Tian et al., 2020; Matencio et al., 2020).

The present overview attempts to give a survey on the novel, special applications of different types of CDs in food technology and nutrition, especially on the beneficial effects of CDs on starchy foods, affecting the retrogradation of starch/amylose systems, providing improved texture quality of bread, noodles, and dough. The presence of certain CDs in starchy foods will not only affect the quality and storability of these products, but in many cases, it will also provide an extra, nutritional value: the presence of added CD to starchy foods will affect the release and absorption of glucose after consumption of these starchy products.

\section{EFFECT OF CYCLODEXTRINS ON STARCH STRUCTURE AND DIGESTION}

The application of CDs in starchy foods can be divided into two major fields:

-CDs act as functional ingredients on the aging/retrogradation of starch in foods, which manifests in the improved quality and usefulness of bakery products, such as bread, dough, pasta, and other similar starch based foods;

-CDs act as active ingredients: they affect oral absorption, enzymatic degradation, and nutritional characteristics of starch-based foods, mainly concerning the after meal glucose levels of starchy food consumption. 


\subsection{Inhibition of retrogradation}

After cooling back a starch solution obtained by heating, the original crystalline structure will not be formed again, but an ordered, only partially crystalline structure is obtained due to retrogradation (arrangement of the linear chains in parallel position, which are fixed by hydrogen bridges) (Wang et al., 2015). Retrograded starch is less soluble and less digestible, therefore, belongs also to resistant starches not digested in the stomach or small intestine and passing on to the large intestine. Retrograded starch has fibre-like properties in digestion.

Components of starch, amylose, and amylopectin are responsible for the short-term and long-term retrogradation, respectively. Crystalline amylose was found to be the nucleus for amylopectin recrystallisation in long-term processes (Keetels et al., 1996).

Retrogradation can be retarded by additives such as CDs. When $\beta$-CD was added to starch, increased swelling and enhanced peak viscosity were observed as well as higher leaching of amylose in consequence of competitive complexation of starch-lipid by CD (Kim and Hill, 1984, 1987). This hypothesis was confirmed more than 30 years later by Gunaratne and Corke (2007, 2008) by using amylose/lysophosphatidylcholine and amylose/stearic acid complexes as models for starch/lipid complexes. As lipids have high affinity for complex formation by CDs (Szente and Fenyvesi, 2017), both $\beta$-CD and hydroxypropyl $\beta$-CD (HP- $\beta$-CD) competed for lipids and therefore, starch/lipid complexes could not be reformed in the presence of CDs (Gunaratne and Corke, 2007, 2008). Tian et al. (2009a) demonstrated that addition of $\beta$-CD to rice starch changed the nucleus core from amylose to amylose-lipid/ $\beta$-CD complex resulting in delayed long-term retrogradation of starch in the presence of $\beta$-CD. Also the short-term retrogradation was retarded by adding $\beta$-CD to instant rice (Tian et al., 2009b; Huang et al., 2013). The effect of HP- $\beta$-CD was more pronounced for wheat starch than for potato starch and for short-term than for long-term retrogradation (Gunaratne et al., 2010). Although the interaction of CD with starch-lipid is dominant, the effect of amylose-CD interaction cannot be excluded either. This would explain the higher mobility of amylose (enhanced leaching) in the presence of CDs. HP$\beta$-CD/amylose complex was detected by differential scanning calorimetry (DSC), and this complex was shown to stabilise amylose against molecular-weight decrease upon storage (Gunaratne et al., 2010). Formation of amylose/ $\beta$-CD/lipid ternary complex was proved by DSC (Yang et al., 2010) and atomic force microscopy (AFM) (Tian et al., 2010).

Similarly to $\beta$-CD, $\alpha$-CD, and $\gamma$-CD may exert anti-aging effects by inhibiting starch retrogradation (Zhou et al., 2019a,b).

Adding $\beta$-CD, maltosyl- $\beta$-CD, and hydroxypropyl- $\beta-\mathrm{CD}$ to rice starches increased the content of slowly digestible starch (SDS) and thermal stability was improved due to the changed crystalline structure (Zan et al., 2013; Tian et al., 2017).

Beneficial effects of CDs can be realised not only by their direct addition to starch, but also by supplementing starch with cyclodextrin glucosyl transferase (CGTase) enzyme, which produces $\alpha-, \beta$-, and $\gamma$-CDs during processing. For instance, non glutinous rice powder was treated with CGTase in water, kneaded, and made into rice cake (Kako et al., 1991). The CD content (1.06\%) was enough to ensure firm texture for a long time. This effect was explained by complexation of CDs with amylopectin via hydrogen bonding and other intermolecular forces and the hindered digestion of the complexed amylopectin, which was transformed into either slowly digestible starch (SDS) or resistant starch (RS) (Li et al., 2019). When corn starch was modified by two enzymes: $\alpha$-D-glucan branching enzyme (GBE) and CGTase simultaneously, 
the digestibility was reduced compared to both native corn starch and single-enzyme treated starch.

CDs, similarly to other polyhydroxy compounds, also increase the gelatinisation temperature of starch due to competition for water, which decreases the availability of water for gelatinisation of starch (D'Appolonia, 1972). During gelatinisation, the intramolecular hydrogen-bonds within starch granules are broken down to be formed again with water molecules. This process results in a gel-like structure, and the dissolution of starch is hindered by CDs.

\subsection{Effect of CDs on starch metabolism}

The easily accessible carbohydrate content of a food is often characterised by its glycaemic index (GI) expressing the rise in blood glucose level $2 \mathrm{~h}$ after consuming the food compared to blood glucose level after consuming glucose only. GI is regarded as a measure of how fast carbohydrates in a food are broken down during digestion. It depends on the type of carbohydrate (e.g. starch has lower GI than white sugar; different starches can have different resistant starch (RS) content and therefore, different GI). Also the fat and protein contents of the food and other factors (e.g. storage conditions) influence the carbohydrate's availability for digesting enzymes. The presence of fat or soluble fibre can slow the gastric emptying rate, thus reducing the GI. Low GI foods are considered healthier than high GI foods. It is especially important to control blood glucose level of people with diabetes.

The GI of $\alpha$ - and $\beta$-CD is practically zero; they are non-digestible in the gastrointestinal tract and only are partially fermented by the colon microflora to maltose and glucose. $\alpha$-CD is almost completely excreted in the faeces of germ-free rats (Van Ommen et al., 2004). So, the metabolic fate of ingested $\alpha$-CD is similar to that of other non-digestible but fermentable carbohydrates such as resistant starch or inulin. No rise in blood glucose was observed after consuming $25 \mathrm{~g}$ $\alpha$-CD dissolved in water (Schmid et al., 2004; Bär et al., 2020). Thus, $\alpha$-CD and similarly also $\beta$-CD comply the definition of dietary fibres (non-digestible by the endogenous enzymes). The dietary fibres have the benefit of changing fat absorption resulting in improved serum lipid profile (reduced cholesterol and triglycerides) as observed for $\alpha$-CD in rats and humans (Suzuki and Sato, 1985; Artiss et al. 2005; Bär et al. 2020).

On the contrary to $\alpha$ - and $\beta$-CD, $\gamma$-CD is readily digested to glucose in the GI tract (de Bie et al., 1998; Munro et al., 2004). However, the rate of hydrolysis by $\alpha$-amylases is decreased when $\gamma$-CD cavity contains a drug or other guest molecule, such as a flavour component (Lumholdt et al., 2012). The enzymatic digestibility could start immediately in the mouth due to the action of amylases (Harangi et al., 2012), but it would be practically zero due to the short time of exposure. The digestion is completed in the small intestine as it was demonstrated in vivo in dogs (Spears et al., 2005) and also in humans (Koutsou et al., 1999). Even though it is digestible, its consumption still results in a reduced postprandial glycaemic response (55\% reduced serum glucose level after meal) compared to maltodextrin as it was found in a human study with 32 subjects consuming $2 \times 25 \mathrm{~g} \gamma$-CD or maltodextrin (Asp et al., 2005, 2006; Lai et al., 2005).

Both $\alpha$ - and $\beta$-CDs are resistant to usual starch degrading enzymes. They bind to the active sites of these enzymes, and as a consequence hinder the hydrolysis of amylose resulting in reduced GI (Szejtli, 1982). Some studies demonstrated that CDs inhibit starch digestion by various amylases, such as fungal glucoamylases, porcine pancreatic amylases, intestinal amylases 
from fishes, bacterial amylases, and barley $\alpha$-amylase (Fukuda et al., 1992; Koukiekolo et al., 2001; Moreau et al., 2001; Mitsuiki et al., 2005; Nielsen et al., 2012). In a human experiment, sucrose diet was supplemented by $\alpha$-CD for healthy young people to discover if $\alpha$-CD inhibits amylases (Gentilcore et al., 2011). Sucrose is hydrolysed by the enzymes in the intestine and not by pancreatic amylases, still reduced glucose and insulin levels were measured compared to control proving that $\alpha$-CD decreases the digestion of carbohydrates not only through inhibition of pancreatic amylases but also by decelerating gastric emptying.

The decreased thermal stability of amylose in the amylose- $\beta$-CD complex and the finding that less $\beta$-CD was extracted suggested that $\mathrm{CD}$ interacted not only with the enzymes but also with starch: $\beta$-CD was likely sandwiched between the helical amylose chains (Yang et al., 2010). These CD-related structural modifications of starch, shown by retarded gelatinisation and dissolution, resulted in reduced amylolytic hydrolysis during digestion (Gunaratne et al., 2010).

Based on the outcomes of several in vitro and in vivo experiments, $\alpha$-CD was concluded to hinder starch digestion, and with this to reduce GI of starch-containing foods. $\alpha$-CD and not $\beta$-CD was selected for these experiments, because $\alpha$-CD can also strongly interact with fatty components of food, such as fatty acids and triglycerides, further enhancing health benefits (Schmid et al., 2004) and has no advisable daily intake (ADI) limit as $\beta$-CD does $(0.5 \mathrm{mg} / \mathrm{kg}$ body weight/day). In 2012, the European Food Safety Authority (EFSA) issued a scientific opinion on the health claims related to reduction of post-prandial glycaemic responses by $\alpha$-CD suggesting to consume at least $5 \mathrm{~g}$ of $\alpha$-CD to each $50 \mathrm{~g}$ of starch to achieve considerable effect (EFSA, 2012).

$\alpha$-CD has been marketed as a dietary fibre ( $\mathrm{FBCx}$, Calorease $\left.{ }^{\mathrm{TM}}\right)$ to be taken 3 times $2 \mathrm{~g}$ consumed together with meal for body weight control. It was useful in human clinical trials on obese people. The weight increase of the group consuming $\alpha$-CD as part of their diet was lower than that of the control group on the same diet without $\alpha$-CD (Grunberger et al., 2007; Comerford et al., 2011). $\alpha$-CD as other soluble fibres reduced insulin secretion and improved the blood lipid profile: decreased serum cholesterol and triglyceride levels. The consumption of $6 \mathrm{~g}$ $\alpha$-CD a day ( $0.2 \%$ dietary intake) in a bigger clinical trial with 75 healthy humans proved that $\alpha$-CD was well tolerated; no serious adverse events related to $\alpha$-CD were observed (Amar et al., 2016). Approximately $8 \%$ of the subjects on $\alpha$-CD complained of minor gastrointestinal symptoms versus $3 \%$ on placebo. Fasting plasma glucose and insulin resistance indices also decreased. Consuming $6 \mathrm{~g} \alpha$-CD a day did not changed microbiota composition of human faecal samples, but reduced the $\mathrm{pH}$ and increased the generation of acetate and propionate suggesting that, even at such relatively low amounts, $\alpha$-CD activated the metabolism of colonic microbiota (Sasaki et al., 2018). The non-digestible carbohydrates, which support the gut flora in the large intestine, are called prebiotics.

In spite of the proved benefits of $\alpha$-CD tablets ( $\mathrm{FBCx}$, later Calorease), these products are not available at present. The provisory market success about 10 years ago was due to marketing on body weight control resulting in probably exaggerating expectations in slimming diets. Some other products containing $\alpha$-CD and marketed as essential fibres, fat binders are still available. The health effects - although not including weight loss - are beyond any doubt.

GlucoFix is another trade name of $\alpha$-CD (GlucoFix, 2021). It is marketed as a completely safe product, which contributes to the reduction of blood glucose rise after starch-containing meals (bread, all flour based products, potatoes and other root vegetables, rice, pasta, cereals, cereal bars, pulses/legumes like beans, peas and lentils, banana, etc.). It is claimed to lower the 
blood sugar increase, thus helping to easily turn carbohydrate rich high-GI foods to low-GI. It is advised to consume together with carbohydrate, preferably mixed into the food.

Although $\gamma$-CD does not influence fat digestion (Spears et al., 2005), it has similar beneficial effects due to delayed and lowered postprandial glucose levels after consumption. Replacing around $1 / 6$ part of corn starch by $\gamma$-CD for 6 weeks, mice showed significantly enhanced voluntary wheel running activity and improved muscle strength (Wupper et al., 2020). The better fitness of the treated mice gives evidence for beneficial health effects of $\gamma$-CD.

\section{CYCLODEXTRIN IN FOODS OF HIGH CARBOHYDRATE CONTENT}

The several applications of CDs in high carbohydrate content foods as carriers of various compounds, such as flavours, fatty acids, essential oils, etc., are not in the scope of the present review. Only the applications of CDs themselves in starchy foods are overviewed.

\subsection{Cyclodextrin in bread}

Branched cyclodextrins have been detected in bread and beer samples as well as in corn syrup using HPLC-MS analysis (Szente et al., 2006). Having found all three branched $\alpha$-, $\beta$-, and $\gamma$-CDs, it was concluded that foods containing enzyme- and heat-processed starch comprised also CDs in a minute amount, suggesting that people have been consuming CDs as minor components of bread and beer for ages. In this subsection the effect of added CDs to bread is overviewed.

CDs can be used in bakery wares and other finished food products, because they remain stable even at high temperatures.

The anti-staling effect of $\alpha$-, $\beta$-, and $\gamma$-CDs was proved in several studies. Staling (firming) of bread involves mainly amylopectin, since the retrogradation of amylose is completed well before the firming associated with staling of bread is observed. Adding CDs to wheat flour-water dough improved dough consistency (Duedahl-Olesen et al., 1999; Tian et al., 2009a), but only $\beta$ - and $\gamma$-CD showed significant anti-staling effect. For instance, after supplying wheat flour-water dough with $3 \mathrm{wt} \% \gamma$-CD, then baking and aging, the melting point of the crystallised amylopectin decreased. Addition of low molecular weight carbohydrates did not show similar effect.

Supplementing wheat flour with different concentrations (0-3 wt $\%)$ of $\beta$-CD improved the properties of both wheat dough and prebaked bread (Zhou et al., 2019a). Dough tensile strength was enhanced and gluten formation improved as the effect of $0.5-1.5 \mathrm{wt} \% \beta$-CD, while higher concentrations were ineffective. Dough fermentation height, gas production volume, and gasholding capacity also increased with the addition of $0-1.5 \mathrm{wt} \% \beta$-CD but not more. $1.5 \mathrm{wt} \%$ $\beta$-CD could also reduce bread hardness and increase bread crumb elasticity and resilience.

Adding $\alpha$-CD and $\gamma$-CD to wheat flour have similar beneficial effects: increased water absorption and shortened times of dough formation and stabilisation, enhanced fermentation height, and gas retention ability of dough were observed (Zhou et al., 2019b). Dough samples containing $2 \mathrm{wt} \% \alpha$-CD or $3 \mathrm{wt} \% \gamma$-CD demonstrated the highest fermentation heights and gas retention volumes, respectively. Also bread hardness was reduced and bread elasticity, resilience, and specific volume improved, and the aging of prebaked bread was delayed. DSC test showed that adding $2 \mathrm{wt} \% \alpha$-CD or $3 \mathrm{wt} \% \gamma-\mathrm{CD}$ reduced significantly the enthalpy of prebaked bread 
samples. The study proved that similarly to $\beta-\mathrm{CD}, \alpha-\mathrm{CD}$ and $\gamma$-CD may exert anti-aging effects by hindering starch retrogradation.

A special way of supplementing bread with CDs is addition of CGTase enzyme, which forms CDs in situ during processing. The beneficial effect of CGTase on the quality of gluten-free (rice) breads was demonstrated by Guyral et al. (2003): higher specific volume, shape index, and better crumb texture were obtained. The forming CDs can complex lipids and proteins and in some extent also starch and this contributes to the hydrolytic activity of the enzyme. CGTase is a useful additive in production of gluten-free bread (Houben et al., 2012).

The changes in structure result in altered digestibility, too. In a human study the effect of $\alpha$-CD on the postprandial glycaemic and insulinaemic effects of starch were investigated (Schmid et al., 2004; Bär et al., 2020). Twelve fasted, healthy male volunteers had, on three subsequent days, a test breakfast consisting of (A) $100 \mathrm{~g}$ fresh white bread (providing $50 \mathrm{~g}$ starch) and $250 \mathrm{~mL}$ drinking water, (B) the same bread with $10 \mathrm{~g} \alpha$-CD dissolved in the drinking water, and (C) $25 \mathrm{~g} \alpha$-CD dissolved in drinking water. Both blood glucose and insulin increased fast after breakfast (A). After breakfast (B), the areas under the curve of blood glucose and insulin were significantly lower (59\% and 57\%, respectively), demonstrating that $\alpha$-CD inhibits starch digestion. No change in the glucose level was observed after breakfast (C). Hence, $\alpha$-CD complies with the current definition of dietary fibre in every respect. As no rebound effect (a fall of blood glucose levels below baseline levels) was observed, a longer lasting satiety feeling can help in reducing food intake and in body weight control.

A clinical trial is going on in 2021 with ten healthy normoglycaemic subjects provided with either a solution of glucose (reference food), bread enriched with $\alpha$-CD, or bread enriched with hydroxytyrosol encapsulated in $\alpha$-CD, with 1-week intervals in amounts that yielded $50 \mathrm{~g}$ of available carbohydrates (Clinical trial, 2021). Venous blood samples will be collected before consumption and at 30, 45, 60, 90, 120, and 180 min postprandially. Postprandial glucose, insulin, and appetite-related hormone responses as well as glycaemic index (GI) and subjective appetite ratings will be evaluated. This study will give evidence on the effect of $\alpha$-CD-supplemented bread, and the data will show also if $\alpha$-CD with a cavity filled with a guest compound (hydroxytyrosol) will maintain the beneficial effects as expected.

\subsection{Cyclodextrin in rice-based products}

Rice is one of the most important components of the daily diet for many people around the world. For some, it acts as the main meal every day.

In enzymatic digestion experiments, rice starch amended with $3 \% \beta-\mathrm{CD}$, maltosyl $\beta-\mathrm{CD}$ or hydroxypropyl $\beta$-CD were compared to reach the conclusion that the native $\beta$-CD-modified starch was degraded in the longest time and gave the lowest GI (Zan et al., 2013).

In a human study, healthy subjects (10) had a diet of boiled white rice containing $50 \mathrm{~g}$ of digestible carbohydrate to which 0 (control), 2, 5, or $10 \mathrm{~g}$ of $\alpha$-CD was added to find that $\alpha$-CD reduced the glycaemic response in a dose-dependent manner (as much as 50\% lower blood glucose levels were achieved after consuming the $10 \mathrm{~g} \alpha$-CD diet). Increasing the dose of $\alpha$-CD greater satiety was felt, but minor gastrointestinal discomfort (stomach ache, bloating, nausea) occurred more often (Buckley et al., 2006).

$\beta$-CD reduces the staling of frozen waxy rice flour dough stored at $-18^{\circ} \mathrm{C}$ for 6 weeks. As an additive, it can slow down the decrease of degree of gelatinisation and the increase of hardness 
and enthalpy, improving the integrity of frozen dough product during storage (Yuan et al., 2008).

CGTase-treated germinated brown rice flour was found to have a positive effect on type-2 diabetic mice and showed also anti-cancer effect on HepG2 cells (Binh et al., 2020).

Some further examples on the use of CD-enabled rice products are listed in Table 1.

\subsection{Cyclodextrin in noodles}

Pasta is a staple food from traditional Italian cuisine and became popular all over the world as part of the healthy Mediterranean diet. It is typically made from unleavened dough of wheat flour mixed with water or eggs, and formed into sheets or other shapes, then cooked by boiling or baking. The main nutrient in pasta (both fresh and dried) is starch.

Adding $\alpha$-CD (2.6\%) to durum wheat (Triticum durum Desf.) semolina (of bigger particle size than flour) to make pasta of increased fibre content, the cooking performance changed: i) surface material released from cooked spaghetti after exhaustive rinsing was substantially higher, even to reach values generally associated with low pasta quality, although it came probably from leaching of $\alpha$-CD only; ii) the optimum cooking time (when the white central core of the pasta just disappeared) was longer, while iii) firmness and water absorption were not significantly affected (Durante et al., 2019). The sensory panel evaluated three textural characteristics of the boiled spaghetti: bulkiness (adhesion of pasta strands to each other), stickiness (amount of material adhering to the spaghetti surface), and strength (resistance to chewing by the teeth). A slight improvement in all three properties was observed, when the $\alpha$-CD-containing pasta was compared to the control.

Applying $0.15 \% \beta$-CD as an optimal anti-aging additive can well retard the starch retrogradation of fresh noodle, resulting in denser and more orderly structure. The enthalpy required by the recrystallisation of melting amylopectin was lower compared to the control group. So, $\beta$-CD as anti-aging additive can maintain the fresh noodle quality and extend its shelf life (Xiao et al., 2016).

Table 1. Some examples on CD-amended rice products

\begin{tabular}{|c|c|c|c|c|}
\hline Product & $\mathrm{CD}$ & $\begin{array}{l}\text { Applied } \\
\text { conc. }\end{array}$ & Benefits & References \\
\hline Rice cake & $\beta-\mathrm{CD}$ & n.s. & Longer shelf life & Pan (2018) \\
\hline Rice cake & n.s. & $5-7.5 \%$ & $\begin{array}{l}\text { Improved nutritive value } \\
\text { and taste }\end{array}$ & $\begin{array}{l}\text { Zhu and Wang } \\
\text { (2019) }\end{array}$ \\
\hline Packed rice cake & n.s. & $0.5-5 \%$ & $\begin{array}{l}\text { Gelatinized starch with } \\
\text { high water content }\end{array}$ & $\begin{array}{l}\text { Fujishiro and } \\
\text { Itou (1987) }\end{array}$ \\
\hline Glutinous rice cake & $\beta-\mathrm{CD}$ & $0.15 \%$ & $\begin{array}{l}\text { Improved nutrition and } \\
\text { taste }\end{array}$ & Changsha (2017) \\
\hline Solid rice shake beverage & $\gamma-\mathrm{CD}$ & n.s. & Good taste, health effects & Zhang (2017) \\
\hline Paste of gelatinized rice & $\beta-\mathrm{CD}$ & $0.15-10 \%$ & $\begin{array}{l}\text { Cracker and other } \\
\text { products of improved } \\
\text { texture }\end{array}$ & $\begin{array}{l}\text { Oofuji and Ogata } \\
\text { (1985) }\end{array}$ \\
\hline $\begin{array}{l}\text { Pie dough, pizza sheets, } \\
\text { noodles, and rice cakes }\end{array}$ & $\begin{array}{c}\text { Highly } \\
\text { branched CDs }\end{array}$ & n.s. & $\begin{array}{l}\text { Improved elasticity and } \\
\text { palatability }\end{array}$ & $\begin{array}{l}\text { Fujishima et al. } \\
\qquad(2001)\end{array}$ \\
\hline
\end{tabular}

n.s. not specified. 


\subsection{Cyclodextrin in other starchy foods}

Potato is a staple food in a large part of the world. Adding as low amount as $2 \% \beta$-CD to potato starch, both plasma glucose and insulin levels in humans (65 and 25\%, respectively) were reduced compared to the control group getting starch only demonstrating that the starch digestion was decelerated (Raben et al., 1997). On the other hand, satiety feeling was also increased.

In the modern kitchen the precooked, vacuum-packed potato is more and more popular, but it is a challenge to preserve the quality. One of the possibilities is to dip potato slices in solutions containing $\beta$-CD, ascorbic and citric acids, either alone or in combination with $\beta$-CD after blanching, and vacuum packaging in pouches (Lante and Zocca, 2010). This treatment results in lighter colour, but the concentration of aerobic mesophilic bacteria is increased.

Some further examples on various starchy foods are listed in Table 2.

\section{CONCLUSIONS}

In this review we summarised the effects of CDs on starch and starchy foods. Based on about 80 references, it was shown how CDs influence the starch structure, inhibit retrogradation and digestibility. CDs, when consumed together with starch and starchy foods, reduce their postprandial glycaemic index through various mechanisms. Several examples illustrate these benefits in bread, including gluten-free products, rice, noodles, pasta and similar products as well as other starch-based products, such as potato, lotus root, and vegetable starches.

Although the three native CDs affect similarly the digestibility of starches, $\alpha$-CD emerged for its beneficial effects on both carbohydrate and fat digestion, and several products have been marketed containing only $\alpha$-CD. On the other hand, $\gamma$-CD is an ideal source of glucose

Table 2. Examples for CD-enabled starch-based products of various origin

\begin{tabular}{|c|c|c|c|c|}
\hline Food & $\mathrm{CD}$ & Conc. & Effect & References \\
\hline Barley cake & $\beta-\mathrm{CD}$ & $1.4-1.6 \%$ & Lowers blood lipid & Hua (2015a) \\
\hline Bean flour & $\alpha-\mathrm{CD}$ & $1-3 \%$ & $\begin{array}{c}\text { Mixed with other } \\
\text { polysaccharides such as, } \\
\text { potato, pumpkin, and } \\
\text { licorice }\end{array}$ & $\begin{array}{l}\text { Zhang et al. } \\
\quad(2017)\end{array}$ \\
\hline Lotus root starch & $\beta-\mathrm{CD}$ & $1.4-1.6 \%$ & $\begin{array}{c}\text { Improved starch } \\
\text { retrogradation, prolonged } \\
\text { storage time, lower blood } \\
\text { lipid }\end{array}$ & Hua (2015b) \\
\hline Sliced purple sweet potato & $\beta-\mathrm{CD}$ & & $\begin{array}{l}\text { Colour preservation, } \\
\text { beneficial health effects }\end{array}$ & Wu (2016) \\
\hline Flour-based foods & $\begin{array}{c}\text { Highly } \\
\text { branched CDs }\end{array}$ & n.s. & Longer storability & $\begin{array}{l}\text { Fujishima et al. } \\
\qquad(2001)\end{array}$ \\
\hline $\begin{array}{l}\text { Vegetable biscuits from } \\
\text { mixed flours }\end{array}$ & $\beta-\mathrm{CD}$ & $0.5-2.0 \%$ & $\begin{array}{l}\text { Dietary fibre, improved } \\
\text { taste }\end{array}$ & Pan et al. (2020) \\
\hline
\end{tabular}

n.s. not specified. 
that has a low impact on blood sugar and blood insulin levels. As it is tolerated well even when taken in large quantities, $\gamma$-CD is an ideal ingredient for food-stuffs with delayed glucose release.

CD-amended starchy foods characterised by delayed digestion will find their place in the healthy diet especially to control and prevent diabetes type- 2 .

\section{ACKNOWLEDGMENTS}

The authors acknowledge the finantial support of Hungarian Research and Innovation Office (2020-1.1.2-PIACI-KFI-2020-00092).

\section{REFERENCES}

Amar, M.J.A., Kaler, M., Courville, A.B., Shamburek, R., Sampson, M., and Remaley, A.T. (2016). Randomized double blind clinical trial on the effect of oral $\alpha$-cyclodextrin on serum lipids. Lipids in Health and Disease, 15: 115. https://doi.org/10.1186/s12944-016-0284-6.

Artiss, J.D., Brogan, K., Brucal, M., Moghaddam, M., and Jen, K.L. (2005). The effects of a new soluble dietary fiber on weight gain and selected blood parameters in rats. Metabolism, 55: 195-202. https://doi. org/10.1016/j.metabol.2005.08.012.

Asp, M., Hertzler, S., and Chow, J. (2005). Effect of gamma-cyclodextrin on postprandial glycemia, insulinemia, and breath hydrogen production in healthy adults. FASEB Journal, 19(Part 1 Suppl. S): A73-A74.

Asp, M.L., Hertzler, S.R., Chow, J., and Wolf, B.W. (2006). Gamma-cyclodextrin lowers postprandial glycemia and insulinemia without carbohydrates malabsorption in healthy adults. Journal of the American College of Nutrition, 25: 49-55. https://doi.org/10.1080/07315724.2006.10719514.

Astray, G., Gonzalez-Barreiro, C., Mejuto, J., Rial-Otero, C.R., and Simal-Gándara, J. (2009). A review on the use of cyclodextrins in foods. Food Hydrocolloids, 23: 1631-1640. https://doi.org/10.1016/j.foodhyd. 2009.01.001.

Astray, G., Mejuto, J.C., and Simal-Gandara, J. (2020). Latest developments in the application of cy-clodextrin host-guest complexes in beverage technology processes. Food Hydrocolloids, 106: 105882. https://doi.org/10.1016/j.foodhyd.2020.105882.

Bär, A., Diamantis, I., and Venetz, W.P. (2020). Alpha-cyclodextrin attenuates the glycemic and insulinemic impact of white bread in healthy male volunteers. Foods, 9: 62. https://doi.org/10.3390/ foods 9010062 .

Binh, N.D.T., Ngoc, N.T.L., Oladapo, I.J., Son, C.H., Thao, D.T., Trang, D.T.X., Ngoc, T.T.A., and Ha, N.C. (2020). Cyclodextrin glycosyltransferase-treated germinated brown rice flour improves the cytotoxic capacity of HepG2 cell and has a positive effect on type-2 diabetic mice. Journal of Food Biochemistry, 44: e13533. https://doi.org/10.1111/jfbc.13533.

Buckley, J.D., Thorp, A.A., Murphy, K.J., and Howe, P.R.C. (2006). Dose-dependent inhibition of the postprandial glycaemic response to a standard carbohydrate meal following incorporation of alphacyclodextrin. Annals of Nutrition and Metabolism, 50: 108-114. https://doi.org/10.1159/000090498.

Changsha, S. (2017). Food preparation method of glutinous rice cake. Chinese Patent Application CN107509919, 2017-12-26. 
Clinical Trial (2021). Postprandial responses to hydroxytyrosol-enriched bread. https://clinicaltrials.gov/ct2/ show/NCT04725955 (last accessed on 03 March 2021).

Comerford, K.B., Artiss, J.D., Jen, K.L.C., and Karakas, S.E. (2011). The beneficial effects alpha-cyclodextrin on blood lipids and weight loss in healthy humans. Obesity, 19: 1200-1204. https://doi.org/10.1038/oby. 2010.280 .

Crini, G. (2014). Review: a history of cyclodextrins. Chemical Reviews, 114: 10940-10975. https://doi.org/ 10.1021/cr500081p.

Crini, G., Fourmentin, S., Fenyvesi, É., Torri, G., Fourmentin, M., and Morin-Crini, N. (2018). Cyclodextrins, from molecules to applications. Environmental Chemical Letters, 16: 1361-1375. https://doi. org/10.1007/s10311-018-0763-2.

D’Appolonia, B.L. (1972). Effect of bread ingredients on starch gelatinization properties as measured by the amylograph. Cereal Chemistry, 49: 532-543.

De Bie, A.T.H.J., Van Ommen, B., and Bär, A. (1998). Disposition of [14C] $\gamma$-cyclodextrin in germ-free and conventional rats. Regulatory Toxicology and Pharmacology, 27: 150-158. https://doi.org/10.1006/rtph. 1998.1219.

Duedahl-Olesen, L., Zimmermann, W., and Delcour, J.A. (1999). Effects of low molecular weight carbohydrates on farinograph characteristics and staling endotherms of wheat flour-water doughs. Cereal Chemistry Journal, 76: 227-230. https://doi.org/10.1094/cchem.1999.76.2.227.

Durante, M., Lenucci, M.S., Gazza, L., Taddei, F., Nocente, F., De Benedetto, G.E., De Caroli, M., Piro, G., and Mita, G. (2019). Bioactive composition and sensory evaluation of innovative spaghetti supplemented with free or $\alpha$-cyclodextrin clathrated pumpkin oil extracted by supercritical $\mathrm{CO}_{2}$. Food Chemistry, 294: 112-122. https://doi.org/10.1016/j.foodchem.2019.05.032.

EFSA (2012). Scientific Opinion on the substantiation of health claims related to alpha-cyclodextrin and reduction of post-prandial glycaemic responses (ID 2926, further assessment) pursuant to Article 13(1) of Regulation (EC) No 1924/2006. EFSA Journal, 10: 2713. https://doi.org/10.2903/j.efsa.2010.1479.

EFSA (2016). Scientific opinion on re-evaluation of $\beta$-cyclodextrin (E 459) as a food additive. EFSA Journal, 14: 4628. https://doi.org/10.2903/j.efsa.2016.4628.

Fenyvesi, É., Vikmon, M., and Szente, L. (2016). Cyclodextrins in food technology and human nutrition: benefits and limitations. Critical Reviews in Food Science and Nutrition, 56: 1981-2004. https://doi.org/ 10.1080/10408398.2013.809513.

Fujishima, N., Kusaka, K., Umino, T., Urushinata, T., and Terumi, K. (2001). Flour based foods containing highly branched cyclodextrins. Japanese Patent Application JP 2001136898, 2001-05-22.

Fujishiro, M. and Itou, N. (1987). Preparation of packed rice cake. Japanese Patent Application JPS62195256, 1987-08-28.

Fukuda, K., Teramoto, Y., Goto, M., Sakamoto, J., Mitsuiki, S., and Hayashida, S. (1992). Specific inhibition by cyclodextrins of raw starch digestion by fungal glucoamylase. Bioscience, Biotechnology, and Biochemistry, 56: 556-559. https://doi.org/10.1271/bbb.56.556.

Gentilcore, D., Vanis, L., Teng, J.C., Wishart, J.M., Buckley, J.D., Rayner, C.K., Horowitz, M., and Jones, K.L. (2011). The oligosaccharide alpha-cyclodextrin has modest effects to slow gastric emptying and modify the glycaemic response to sucrose in healthy older adults. British Journal of Nutrition, 106: 583587. https://doi.org/10.1017/S0007114511000444.

GlucoFix (2021). glucofix.com. (last accessed on 03 February 2021).

Grunberger, G., Jen, K.L., and Artiss, J.D. (2007). The benefits of early intervention in obese diabetic patients with FBCx: a new dietary fibre. Diabetes/Metabolism Research and Reviews, 23: 56-62. https:// doi.org/10.1002/dmrr.687. 
Gujral, H.S., Guardiola, I., Carbonell, J.V., and Rosell, C.M. (2003). Effect of cyclodextrinase on dough rheology and bread quality from rice flour. Journal of Agricultural and Food Chemistry, 51: 3814-3818. https://doi.org/10.1021/jf034112w.

Gunaratne, A., and Corke, H. (2007). Influence of unmodified and modified cycloheptaamylose ( $\beta$ cyclodextrin) on transition parameters of amylose-lipid complex and functional properties of starch. Carbohydrate Polymers, 68: 226-234, https://doi.org/10.1016/j.carbpol.2006.12.017.

Gunaratne, A. and Corke, H. (2008). Effect of hydroxypropyl beta-cyclodextrin on physical properties and transition parameters of amylose-lipid complexes of native and acetylated starches. Food Chemistry, 108: 14-22. https://doi.org/10.1016/j.foodchem.2007.07.010.

Gunaratne, A., Kong, X., and Corke, H. (2010). Functional properties and retrogradation of heat-moisture treated wheat and potato starches in the presence of hydroxypropyl $\beta$-cyclodextrin. Starch - Stärke, 62: 69-77. https://doi.org/10.1002/star.200900193.

Harangi, J., Beke, G., Harangi, M., and Motyan, J.A. (2012). The digestable parent cyclodextrin. Journal of Inclusion Phenomena and Macrocyclic Chemistry, 73: 335-339. https://doi.org/10.1007/s10847-0110061-0.

Houben, A., Höchstötter, A. and Becker, T. (2012). Possibilities to increase the quality in gluten-free bread production: an overview. European Food Research and Technology, 235: 195-208. https://doi.org/10. 1007/s00217-012-1720-0.

Hua, X. (2015a). Highland barley cake and preparation method thereof. Chinese Patent Application CN105123846, 2015-12-09.

Hua, X. (2015b). Blood sugar-lowering cake and preparation method thereof. Chinese Patent Application CN105123848, 2015-12-09.

Huang, M., He, G., Chen, S., Cui, M., Ma, L., and Liu, Y. (2013). Optimisation of a quality improver for instant rice and its quality properties. International Journal of Food Science \& Technology, 49: 606-615. https://doi.org/10.1111/ijfs.12343.

Kako, N., Kitagawa, H., Sato, T., Akano, H., Okumura, H., and Kawamura, K. (1991). Cyclodextrin-containing processed starch, its use and production. Japanese Patent Application JPH0383549, 1991-04-09.

Keetels, C.J.A.M., Van Vliet, T., Jurgens, A., and Walstra, P. (1996). Effects of lipid surfactants on the structure and mechanics of concentrated starch gels and starch bread. Journal of Cereal Science, 24: 33-45, https://doi.org/10.1006/jcrs.1996.0035.

Kim, H.O. and Hill, D. (1984). Physical characteristics of wheat starch granule gelatinization in the presence of cycloheptaamylose. Cereal Chemistry, 61: 432-435.

Kim, H.O. and Hill, R.D. (1987). Effect of cyclomaltoheptaose on amylose-lipid complexes during wheat-starch pasting. Carbohydrate Research, 170: 215-228. https://doi.org/10.1016/s0008-6215(00) 90906-6.

Koukiekolo, R., Desseaux, V., Moreau, Y., Marchis- Mouren, G., and Santimone, M. (2001). Mechanism of porcine pancreatic $\alpha$-amylase: inhibition of amylose and maltopentaose hydrolysis by alpha-, beta- and gamma-cyclodextrins. European Journal of Biochemistry, 268: 841-848. https://doi.org/10.1046/j.14321327.2001.01950.x.

Koutsou, G.A., Storey, D.M., and Bär, A. (1999). Gastrointestinal tolerance of $\gamma$-cyclodextrin in humans. Food Additives \& Contaminants, 16: 313-317. https://doi.org/10.1080/026520399283984.

Lai, C.S., Chow, J., and Wolf, B.W. (2005). Methods of using gamma-cyclodextrin to control blood glucose and insulin secretion. U.S. Patent Application US 2005215523, 2005-09-29.

Lante, A. and Zocca, F. (2010). Effect of $\beta$-cyclodextrin addition on quality of precooked vacuum packed potatoes. LWT - Food Science and Technology, 43: 409-414. https://doi.org/10.1016/j.lwt.2009.09.002. 
Li, Y., Li, C., Gu, Z., Cheng, L., Hong, Y., and Li, Z. (2019). Digestion properties of corn starch modified by $\alpha$-D-glucan branching enzyme and cyclodextrin glycosyltransferase. Food Hydrocolloids, 89: 534-541. https://doi.org/10.1016/j.foodhyd.2018.11.025.

Lumholdt, L.R., Holm, R., Jørgensen, E.B., and Larsen, K.L. (2012). In vitro investigations of alpha-amylase mediated hydrolysis of cyclodextrins in the presence of ibuprofen, flurbiprofen, or benzo[a]pyrene. Carbohydrate Research, 362: 56-61. https://doi.org/10.1016/j.carres.2012.09.018.

Martina, K., Binello, A., Lawson, D., Jicsinszky, L., and Cravotto, G. (2013). Recent applications of cyclodextrins as food additives and in food processing. Current Nutrition \& Food Science, 9: 167-179. https://doi.org/10.2174/1573401311309030001.

Matencio, A., Navarro-Orcajada, S., García-Carmona, F., and López-Nicholas, J.M. (2020). Applications of cyclodextrins in food science. A review. Trends in Food Science and Technology, 104: 132-143. https:// doi.org/10.1016/j.tifs.2020.08.009.

Mitsuiki, S., Mukae, K., Sakai, M., Goto, M., Hayashida, S., and Furukawa, K. (2005). Comparative characterization of raw starch hydrolyzing alpha-amylases from various Bacillus strains. Enzyme and Microbial Technology, 37: 410-416. https://doi.org/10.1016/j.enzmictec.2005.02.022.

Moreau, Y., Desseaux, V., Koukiekolo, R., Marchis-Mouren, G., and Santimone, M. (2001). Starch digestion in tropical fishes: isolation, structural studies and inhibition kinetics of $\alpha$-amylases from two tilapias Oreochromis niloticus and Sarotherodon melanotheron. Comparative Biochemistry \& Physiology, Part B: Biochemistry \& Molecular Biology, 128B: 543-552. https://doi.org/10.1016/s10964959(00)00358-4.

Moreira da Silva, A. (2018). Room at the top as well as at the bottom: structure of functional food inclusion compounds. In: Aurora, P. and Dhingra, N. (Eds.), Cyclodextrin: a versatile ingredient. Intechopen, Vienna, pp. 553-573. https://doi.org/10.5772/intechopen.74162.

Munro, I., Newberne, P.M., Young, V.R., and Bär, A. (2004). Safety assessment of $\gamma$-cyclodextrin. Regulatory Toxicology and Pharmacology, 39(Suppl. 1): S3-S13. https://doi.org/10.1016/j.yrtph.2004. 05.008.

Nielsen, J.W., Kramhoeft, B., Bozonnet, S., Abou, H., Maher, S.S.L.S., Svensson, B., and Willemoes, M. (2012). Deagradation of the starch components amylopectin and amylose by barley alpha-amylase 1 . Role of surface binding site 2. Archives of Biochemistry and Biophysics, 528: 1-6. https://doi.org/10. 1016/j.abb.2012.08.005.

Oofuji, T. and Ogata, K. (1985). Method for making rice into paste. Japanese Patent Application JPS60203150, 1985-10-14.

Pan, H. (2018). Preparation method of rice cake with eyesight promoting and stomach nourishing effects. Chinese Patent Application CN108094872, 2018-06-01.

Pan, Y., Chen, R., Xu, H., Song, J., Lai, R., Bai, Y., Shi, Q., Xu, H., Zhang, Z., and Li, X. (2020). Non-bitter wild vegetable biscuits and preparation method thereof. CN111616183, 2020-09-04.

Raben, A., Andersen, K., Karberg, M.A., Holst, J.J., and Astrup, A. (1997). Acetylation of or $\beta$-cyclodextrin addition to potato starch: beneficial effect on glucose metabolism and appetite sensations. American Journal of Clinical Nutrition, 66: 304-314. https://doi.org/10.1093/ajcn/66.2.304.

Sasaki, D., Sasaki, K., Ikuta, N., Yasuda, T., Fukuda, I., Kondo, A., and Osawa, R. (2018). Low amounts of dietary fibre increase in vitro production of short-chain fatty acids without changing human colonic microbiota structure. Scientific Reports, 8: 435. https://doi.org/10.1038/s41598-017-18877-8.

Schmid, G., Reuscher, H., and Antlsperger, G. (2004). Method for reducing the glycemic index of food. European Patent Application EP 1447 013, 2004-08-08. 
Spears, J.K., Karr-Lilienthal, L.K., Grieshop, C.M., Flickinger, E.A., Wolf, B.W., and Fahey, G.C. (2005). Pullulans and $\gamma$-cyclodextrin affect apparent digestibility and metabolism in healthy adult ileal cannulated dogs. Journal of Nutrition, 135: 1946-1952. https://doi.org/10.1093/jn/135.8.1946.

Suzuki, M. and Sato, A. (1985). Nutritional significance of cyclodextrins: indigestibility and hypolipemic effect of alpha-cyclodextrin. Journal of Nutritional Science and Vitaminology, 31: 209-223.

Szejtli, J. (1982). Cyclodextrins and their inclusion complexes. Akadémiai Kiadó, Budapest, p. 296.

Szejtli, J. (1988). Cyclodextrin technology. Springer, Netherlands. https://doi.org/10.1007/978-94-0157797-7.

Szejtli, J. (1991). Helical and cyclic structures in starch chemistry. ACS Symposium Series, 458 (Biotechnol.Amylodextrin Oligosaccharides): 2-10. https://doi.org/10.1021/bk-1991-0458.ch001.

Szejtli, J. (2004). Cyclodextrins and molecular encapsulation. In: Nalwa. H.S. (Ed.), Encyclopedia of nanoscience and nanotechnology, Vol. 2. American Scientific Publishers, pp. 283-304.

Szente, L. and Fenyvesi, É. (2017). Cyclodextrin-lipid complexes: cavity size matters. Structural Chemistry, 28: 479-492. https://doi.org/10.1007/s11224-016-0884-9.

Szente, L., Harangi, J., Greiner, M., and Mandel, F. (2006). Cyclodextrins found in enzyme- and heatprocessed starch-containing foods. Chemistry \& Biodiversity, 3: 1004-1014. https://doi.org/10.1002/ cbdv.200690098.

Szente, L. and Szejtli, J. (2004). Cyclodextrins as food ingredients. Trends in Food Science and Technology, 15: 137-142. https://doi.org/10.1016/j.tifs.2003.09.019.

Tian, Y., Xu, X., Li, Y. Jin, Z., Chen, H., and Wang, H. (2009a). Effect of $\beta$-cyclodextrin on the long-term retrogradation of rice starch. European Food Research and Technology, 228: 743-748. https://doi.org/10. 1007/s00217-008-0985-9.

Tian, Y., Li, Y., Manthey, F.A., Xu, X., Jin, Z., and Deng, L. (2009b). Influence of $\beta$-cyclodextrin on the short-term retrogradation of rice starch. Food Chemistry, 116: 54-58. https://doi.org/10.1016/j. foodchem.2009.02.003.

Tian, Y., Wang, S., Tong, Q., and Zhan, J. (2017). Thermal and crystalline properties of slowly digestible starch prepared from the starches physically modified by $\beta$-cyclodextrins. Starch - Stärke, 69: 1500370. https://doi.org/10.1002/star.201500370.

Tian, B., Xiao, D., Hei, T., Ping, R, Hua, S., and Liu, J. (2020). The application and prospects of cyclodextrin inclusion complexes and polymers in the food industry: a review. Polymer International, 69: 597-603. https://doi.org/10.1002/pi.5992.

Tian, Y., Yang, N., Li, Y., Xu, X., Zhan, J., and Jin, Z. (2010). Potential interaction between $\beta$-cyclodextrin and amylose-lipid complex in retrograded rice starch. Carbohydrate Polymers, 80: 581-584. https://doi. org/10.1016/j.carbpol.2009.12.010.

Van Ommen, B., De Bie, A.T.H.J., and Bär, A. (2004). Disposition of 14C-alpha-cyclodextrin in germ-free and conventional rats. Regulatory Toxicology and Pharmacology, 39: S57-S66. https://doi.org/10.1016/j. yrtph.2004.05.011.

Wang, S., Li, C., Copeland, L., Niu, Q., and Wang, S. (2015). Starch retrogradation: a comprehensive review. Comprehensive Reviews in Food Science and Food Safety, 14: 568-585. https://doi.org/10.1111/15414337.12143.

$\mathrm{Wu}, \mathrm{Y}$. (2016). Preparation method of edible purple sweet potato products. Chinese Patent Application CN106072163, 2016-11-09.

Wupper, S., Fischer, A., Luersen, K., Ipharraguerre, I.R., Chikamoto, K., Furune, T., Ishida, Y., Terao, K., and Rimbach, G. (2020). Effects of dietary gamma-cyclodextrin on voluntary activity and muscle 
strength in mice. Journal of Physiology and Pharmacology, 71(3): 373-382. http://jpp.krakow.pl/journal/ archive/06_20/pdf/10.26402/jpp.2020.3.08.pdf (last accessed on 01 March 2021).

Xiao, D., Zhou, W.-H., Deng, H., and Huang, Y. (2016). Inhibition mechanism against retrogradation of fresh wet noodle by emulsifiers. Modern Food Science and Technology, 32: 118-124. http://www.tcsae. org/nygcxb/ch/reader/view_abstract.aspx?doi=10.11975/j.issn.1002-6819.2015.23.035 (last accessed on 28 February 2021).

Yang, Y., Gu, Z., Xu, H., Li, F., and Zhang, G. (2010). Interaction between amylose and beta-cyclodextrin investigated by complexing with conjugated linoleic acid. Journal of Agricultural and Food Chemistry, 58: 5620-5624. https://doi.org/10.1021/jf9043869.

Yuan, B., Huang, W., and Zou, Q. (2008). Staling characteristics and glass transition temperature of frozen waxy rice flour dough. ShipinKexue (Beijing, China), 29: 53-57 (in Chinese). Chemical Abstracts, 152: 143063.

Zan, J., Tian, Y., and Tong, Q. (2013). Preparation and slowly digestible properties of beta-cyclodextrinsmodified starches. Carbohydrate Polymers, 91: 609-612. https://doi.org/10.1016/j.carbpol.2012.08.051.

Zhang, Y. (2017). Solid rice shake beverage containing hericiumerinaceus, and preparation method thereof. Chinese Patent Application CN107467467, 2017-12-15.

Zhang, Y., Shao, Z., Qiu, H., Zhao, H., Wang, Y., Gao, J., Liu, L., Zhang, Y., and Wu, L. (2017). Inonotus obliquus polysaccharide composite bean flour and preparation method thereof. Chinese Patent Application CN106616372, 2017-05-10.

Zhou, J., Yang, H., Qin, X., Hu, X., Liu, G., and Wang, X. (2019a). Effect of $\beta$-cyclodextrin on the quality of wheat flour dough and prebaked bread. Food Biophysics, 14: 173-181. https://doi.org/10.1007/s11483019-09566-2.

Zhou, J., Ke, Y., Barba, F. J., Xiao, S., Hu, X., Qin, X., Ding, W., Lyu, Q., Wang, X., and Liu, G. (2019b). The addition of $\alpha$-cyclodextrin and $\gamma$-cyclodextrin affect quality of dough and prebaked bread during frozen storage. Foods, 8: 174. https://doi.org/10.3390/foods8050174.

Zhu, T. and Wang, B. (2019). Rice cake premix flour and preparation method thereof. Chinese Patent Application CN110521744, 2019-12-03.

Open Access. This is an open-access article distributed under the terms of the Creative Commons Attribution-NonCommercial 4.0 International License (https://creativecommons.org/licenses/by-nc/4.0/), which permits unrestricted use, distribution, and reproduction in any medium for non-commercial purposes, provided the original author and source are credited, a link to the CC License is provided, and changes - if any - are indicated. 